\title{
Germination of Seeds exposed to Low Temperatures.
}

\author{
By H. F. Roberts, University of Manitoba.
}

THIS investigation was undertaken in December I92I. Seeds of thirty species were placed in tin containers (druggists' ointment tins), one lot being left indoors in the laboratory, at a temperature of $75^{\circ} \mathrm{F}$., the other lot being exposed out of doors, for 83 days, from January 9 to April 2. In both cases the seeds were kept perfectly dry. After the conclusion of the period indicated, the seeds of both lots were germinated between blotters for io days in the laboratory, at a temperature of $72^{\circ}-75^{\circ} \mathrm{F}$. One hundred seeds were tested from each lot, the germinated seeds being counted on the fifth, seventh, and tenth days. Fifteen varieties of garden seeds, belonging to seven species, gave a germination percentage at the end of Io days of 67 per cent. to 63 per cent. in favour of the indoor lots. For eleven varieties, belonging to eight species, the germination percentage at the end of Io days was as 70 per cent. to 66 per cent., also in favour of the indoor lots. The twenty-six varieties gave an average percentage germination at the end of 5,7 , and Io days of $42: 36$, $62: 58$, and $69: 65$ respectively, for the indoor and the outdoor lots, or a preponderant percentage superiority of 6 per cent., 4 per cent., and 4 per cent. respectively, for the three successive periods, in favour of the lots kept indoors.

From the above summary, it appears that a small average increased germination percentage occurred in the case of seeds kept at laboratory temperature. It was noticed that the seeds of cool temperate species developed a germination percentage higher by 25 per cent. (54:20) than those of the warm temperate species kept at laboratory temperature, during the first 5 days of the germination period, although the increased percentage was but I 4 per cent. $(43: 29)$ in favour of the same group exposed to the outside winter temperature. The total germination percentage, however, was approximately the same in both cases.

The mean temperature out of doors for the period of the experiment was as follows, in degrees Fahrenheit: Jan. +3.0, Feb. +o.4, Mar. +24.7, Apr. + 4r.5, May $+60 \cdot 0$.

In the winter of I923, another lot, consisting of fourteen species, in thirty-three varieties, all of them cool temperate vegetable and field seeds, were exposed as before on January 26. On May 12 the different lots of seeds were tested for percentage of germination. In the preceding year's experiment the germination test was made in the laboratory for plant physiology of the University of Manitoba. In the second year the germination tests were conducted in the official Dominion Seed Laboratory at Winnipeg. The results obtained were as follows: As the average of the summary shows, there was a difference of 4 per cent. in favour of the seeds kept at laboratory temperature,- - about 2 per cent. less than the average at the end of Io days for the twenty-six species and varieties tested the preceding year. At all events, the results, although not conclusive, at least point to a slight diminution in total vitality, as the result of continued exposure to low winter temperatures at the latitude of Manitoba. It should be stated that all the seeds tested were in a thoroughly air-dry condition before the beginning of the test.

Sixty-six varieties, belonging to fifteen species, were tested, including carrot, Swedish turnip, mangel, sugar beet, barley, flax, crimson and white clover, cucumber, cauliflower, celery, egg plant, and cabbage. The total averages for all varieties tested were as follows :

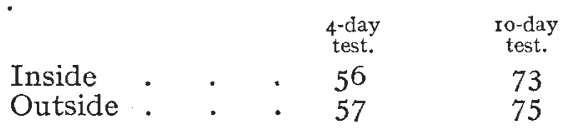

There is therefore seen to be practically no difference in the results as between the seeds kept indoors and those kept outside. If some of the individual cases are examined separately, three varieties of carrots gave at the final test 69 per cent. and 68 per cent. respectively for the seeds outside and inside; six varieties of Swedish turnip, 75 per cent. and 75 per cent.; three varieties of mangels, 56 per cent. and 62 per cent. ; three varieties of turnip, $7 \mathrm{I}$ per cent. and 73 per cent.; three varieties of cucumber, 79 per cent. and $8 \mathrm{I}$ per cent. ; four varieties of cabbage, 98 per cent. and 77 per cent.

It thus appears, when the details can be taken in numbers sufficient to indicate an average result, that the data agree with the general average. Inasmuch as the data herein are at variance with the general experience of practical men, horticulturists, etc., with regard to the practical utility of chilling seeds, it is concluded that the general factor of moisture is the effective one, and that the layering of seeds in a moist substratum accounts for the effectiveness of the practice, rather than the temperature factor alone.

\section{Barogram Analysis in Weather Forecasting.}

THE Italian meteorologist, Francesco Vercelli, has made a laborious study of barographic records from various parts of the world, and various periods and seasons, submitting these curves to a process of periodigram analysis on the lines familiar in tidal investigations, or as applied to the study of seiches in lakes by the late Prof. Chrystal. The results are described in full detail in a booklet published last year in Rome, under the auspices of the Geophysical Institute of Trieste, entitled "Nuovi esperimenti di previsioni meteorologiche."

From the generalised point of view, the barometric curves are shown to contain the well-known diurnal period which is so outstanding in the tropics, various periods ranging between a few days and a month, and an annual period, together with a small " insoluble residue," representing what must be regarded as irregular fluctuations. The amplitudes of these several periods, and other characteristics thereof, differ greatly according to latitude, season, and continentality. If the periodal composition of a given barogram is known, it becomes possible to synthesise its prolongation on the assumption that none of the contained periods die out or others reappear, and thus to make a forecast of the course of barometric pressure for a longer period than is possible by the ordinary synoptic chart method.

Vercelli claims - and the responsibility for the statement must rest with him-to have obtained remarkably good agreement between the predicted and actual continuations of his curves, and to have used this method of weather forecasting with much success in circumstances of grave responsibility on the Italian Front during the War. He indicates the main source of error to be the liability to cessation, or temporary suspension, of any of the component periods, or the reappearance of others. $\mathrm{He}$ also points out that the paper in question, discussing the analysis of

No. 2863 , voL. I I 4$]$ 